\title{
El sistema jurídico y la violencia: una perspectiva ambiental
}

\author{
Pierre Foy Valencia* \\ La humanidad no puede liberarse de la violencia \\ más que por medio de la no violencia. \\ Mahatma Gandhi
}

Sumario: 1. Motivación. 2. Un rastreo de la relación violencia / ambiente (I): reencuentro de concepciones y reinterpretaciones de la realidad que impactan a los sistemas jurídicos. 3. Un rastreo de la relación violencia / ambiente (II): la crisis climática consecuencia antropogénica. 4. Un rastreo de la relación violencia / ambiente (III): otras afectaciones al ambiente independientemente del cambio climático. 5. Una interrogante epistemológica ¿se puede hablar de violencia contra la naturaleza? (¿homini lupus natura?). 6. ¿Cómo intervienen los sistemas jurídicos en esta relación violencia ambiente. 7. ¿La violencia de los conflictos socioambientales? 8. Ultílogo. Derechos, desastre y ambiente. Una expresión de la relación: derecho / violencia y ambiente. 9. Conclusión.

\section{Motivación}

La reflexión crítica y académica sobre las relaciones entre derecho y violencia es esencialmente compleja. Una primera aproximación elemental podría ser partir de la teoría de las fuentes del Derecho, ya sea en términos de fuentes materiales (v.g. la violencia como fenómeno interdisciplinario ${ }^{1}$ ), como de fuentes formales (v.g. doctrinarios: los derechos humanos y la violencia ${ }^{2}$; normativos y jurisprudenciales: la sanción penal por las conductas

* Profesor asociado de la Facultad de Derecho de la Pontificia Universidad Católica del Perú, en Derecho Ambiental. Master en Derecho Ambiental por la Universidad del País Vasco. Miembro y fundador del Instituto de Estudios Ambientales (IDEA-PUCP).

1 AA. VV. - UNESCO. La violencia y sus causas. Paris: Editorial de la UNESCO, 1981. Mac Gregor, Felipe, Marcial Rubio y Máximo Vega-Centeno. Marco teórico y conclusiones de la investigación sobre violencia estructural. Lima: APEP, 1990.

2 RABOSSI, Eduardo. «Notas sobre la globalización, los derechos humanos y la violencia». En Justicia global, derechos humanos y responsabilidad. Bogotá: Siglo del Hombre, Universidad de Antioquia: 2007, pp. 231-247. 
violentas $\left.{ }^{3}\right)$. Desde nuestra perspectiva jus disciplinaria ${ }^{4}$ esta aproximación nos conduce a consideraciones temáticas como la paz por oposición a la violencia y en ese sentido el imperativo de abordar concepciones relativas al pacifismo y la no violencia, que servirán de sustento para postular expresiones formalizadas (juridificadas) acerca de la violencia y el ambiente ${ }^{5}$. Al respecto, la cultura de la no violencia se alimenta y encuentra profundamente arraigada en los movimientos ecologistas (ecopacifismo) ${ }^{6}$, teniendo entre su mentores a Gandhi, Schumacher, al propio Einstein —añadiríamos al «viejo» Russell— a Vandana Shiva ${ }^{7}$ en tiempos recientes ${ }^{8}$, por mencionar algunos?

3 SÁnChez Tomás, José Miguel. La violencia en el derecho penal: su análisis jurisprudencial y dogmático en el CP 1995. Barcelona: Bosch, 1999. For ValenCIA. Pierre. «Aproximaciones y estimativas al estudio de la criminalidad y el Derecho Penal Ambiental Peruano». Derecho PUC, N 46, diciembre 1992, pp. 257-274.

4 Derecho Ambiental y Ecología Política.

5 El concepto de ambiente, siempre polémico en cuanto a su caracterización, tiene diferentes acepciones. La Ley General del Ambiente, Ley 28611 al referirse a su ámbito en el artículo 2, refiere que: [...].-2.3 Entiéndese, para los efectos de la presente Ley, que toda mención hecha al «ambiente» o a «sus componentes» comprende a los elementos físicos, químicos y biológicos de origen natural o antropogénico que, en forma individual o asociada, conforman el medio en el que se desarrolla la vida, siendo los factores que aseguran la salud individual y colectiva de las personas y la conservación de los recursos naturales, la diversidad biológica y el patrimonio cultural asociado a ellos, entre otros.

6 Tello, Enric. «Ecopacifismo: una visión política emergente». En Joan Antón MelLón (editor). Ideologías y movimientos políticos contemporáneos. Madrid: Tecnos, 1998. pp. 339-381. SOSA, Nicolás. «Ética ecológica y movimientos sociales». En Jesús BallesTeros y José Pérez Adán. Sociedad y medio ambiente. Madrid: Trotta, 1997, pp. 271-299.

7 Vandana Shiva es una activista india, escritora e intelectual. Entre sus libros se encuentran Water Wars: Pollution, Profits and Privatization: The Plunder of Nature and Knowledge y The Hijacking of the Global Food Supply. Earth Democracy: Justice, Sustainability, and Peace.

8 «Gandhi revivido: el ecologismo de los pobres de la tierra». En TelLo, Ob. cit., pp. 378-381.

$9 \quad$ En los principales documentos sobre el desarrollo sostenible se aprecia el rol que se le asigna a la paz:

Declaración de la Conferencia de las Naciones Unidas sobre el Medio Ambiente Humano Estocolmo, 5 al 16 de junio de 1972. Proclama 6 [...] «La defensa y el mejoramiento del medio ambiente humano para las generaciones presentes y futuras se han convertido en meta imperiosa de la humanidad, y ha de perseguirse al mismo tiempo que las metas fundamentales ya establecidas de la paz y el desarrollo económico y social en todo el mundo, y de conformidad con ellas».

Declaración de Río sobre el Medio Ambiente y el Desarrollo PRINCIPIO 25

«La paz, el desarrollo y la protección del medio ambiente son interdependientes e inseparables».

Programa 21: Capítulo 36. 36. FOMENTO DE LA EDUCACIÓN, LA CAPACITACIÓN Y LA TOMA DE CONCIENCIA

Áreas de programas B. Aumento de la conciencia del público. Actividades. [...] «36.10. Reconociendo que los países y las organizaciones regionales e internacionales deter- 


\title{
2. Un rastreo de la relación violencia / ambiente (I): reencuentro de concepciones y reinterpretaciones de la realidad que impactan a los sistemas jurídicos ${ }^{10}$
}

\author{
Desde una perspectiva histórica, la compleja relación hombre-ambiente \\ se remonta a los orígenes de las sociedades y culturas, relación que se ha \\ desarrollado de manera interactuante. De una parte, las actividades huma- \\ nas permanentemente han estado condicionadas por el entorno natural y \\ ecológico (v.g., las sociedades hidráulicas o culturas como la andina) ${ }^{11}$. De \\ la otra, dichos entornos han sido impactados de los modos más diversos, \\ como en el caso de la creación de las ciudades y en general de todo el \\ proceso de avance de la «tecnósfera» (esfera creciente de intervención de la \\ actividad humana expresada a través de la técnica).
}

minarán sus propias prioridades y plazos de aplicación de conformidad con sus necesidades, políticas y programas, se proponen las siguientes actividades: I) Se debería aumentar la conciencia del público acerca de las consecuencias de la violencia en la sociedad».

La carta de la Tierra. Preámbulo «Estamos en un momento crítico de la historia de la Tierra, en el cual la humanidad debe elegir su futuro. A medida que el mundo se vuelve cada vez más interdependiente y frágil, el futuro depara, a la vez, grandes riesgos y grandes promesas. Para seguir adelante, debemos reconocer que en medio de la magnífica diversidad de culturas y formas de vida, somos una sola familia humana y una sola comunidad terrestre con un destino común. Debemos unirnos para crear una sociedad global sostenible fundada en el respeto hacia la naturaleza, los derechos humanos universales, la justicia económica y una cultura de paz. En torno a este fin, es imperativo que nosotros, los pueblos de la Tierra, declaremos nuestra responsabilidad unos hacia otros, hacia la gran comunidad de la vida y hacia las generaciones futuras» [...] V. DemOCRACIA, NO VIOlenCIA y PAZ [...] 16. "Promover una cultura de tolerancia, no violencia y paz».

10 For Valencia, Pierre. «Consideraciones sobre el impacto de la crisis ambiental y de los nuevos paradigmas en los sistemas jurídicos contemporáneos». Revista del Foro. Colegio de Abogados de Lima, Año LXXX, N 1, 1992, pp. 277- 287. Del mismo autor «En busca del Derecho Ambiental (I)». En: For Valencia (editor). Derecho y ambiente. Aproximaciones y estimativas. Lima: PUCP, 1997, pp. 41-42. Para una revisión crítica de posmodernos paradigmas, ver MOSTERIIN, Jesús. Crisis de los paradigmas en el siglo XXI. Lima: UNE y UIGV, 2006.

11 Bramwell, Anna. Ecology in the 20th Century: A History. New Haven, London: Yale University Press, 1989. Gı lao, Nicolo y Jorge Morello. «Notas sobre la historia ecológica de la América Latina». En Osvaldo Sunkel. Estilos de desarrollo y medio ambiente en América Latina, tomo I. México: FCE, 1980, pp. 129-157. Ver, asimismo, de Luis VitALE. Hacia una historia del medio ambiente en América latina. Caracas: Editorial Nueva Sociedad, 1983, Algunos enfoques tradicionales no pierden cierta actualidad o interés, resultando un tanto pioneros, como serían las obras de Emil LudwiG. El Mediterráneo, la leyenda de un mar. Buenos Aires: Editorial Hemisferio, 1952; o El Nilo, biografía de un río. Santiago de Chile: Ediciones Ercilla, 1942. 
Para algunos, la crisis ecológica contemporánea representa —entre otros aspectos- el proceso por el cual la biósfera (capa de organismos vivientes) se retrae ante el avance de la tecnósfera (una suerte de "nueva capa planetaria» creada por el hombre) a expensas de aquella. Esta tensión histórica no siempre es apreciada con la ponderación debida, no faltando ciertos radicalismos críticos o puristas que denostan acerca del rol del progreso y las ventajas del bienestar. ${ }^{12}$

Ciertamente, no se trata de polarizar o satanizar determinadas respuestas tecnológicas versus naturismos a ultranza, sino más bien de limitar las conductas humanas para un adecuado manejo de la biósfera. Después de todo, en cierto modo, despilfarrar o hacer un mal uso de los recursos puede representar una forma belicosa, como refería Schumacher ${ }^{13}$ de atentar contra la base ecosistémica sobre la cual se sostiene el valor vida.

Se podría afirmar que las fuentes que sostienen los elementos paradigmáticos de la posmodernidad, se encuentran expresados en una diversidad de desarrollos «disciplinarios, que tienden a confluir e integrarse, tanto en el campo de las denominadas ciencias naturales, como de las culturas, para emplear una antigua denominación del filósofo Ernst Cassirer ${ }^{14}$; en algún momento el propio Jean Piaget postuló un sistema de conocimientos y de ciencias integrado ${ }^{15}$. A su turno, las ciencias sociales a través del redescubrimiento del otro, el develamiento de la diversidad y el reencuentro con la unidad ${ }^{16}$, así como el estudio comparado de las religiones ${ }^{17}$, también

12 Tolba, Mostafá refiere que habrían tres tipos de percepciones sobre el ambientalismo: a) la que insiste en la búsqueda de soluciones legales y técnicas y que por la vía de la convicción y participación puede reformar el sistema; b) la de quienes no creen que fuese tan sencilla la salida, generándose grupos de presión en la toma de decisiones, y c) la de los que critican la base tecnológica y energética de la sociedad actual reclamando tecnologías alternativas o «blandas» y el incremento de la autosuficiencia. Salvemos el planeta: problemas y esperanzas. London: Chapman \& Hall, 1992, pp. 234-235. E. F. SChumacher. Lo pequeño es hermoso. Madrid: Herman Blume, 1986, pp. 45 y ss.

14 Las ciencias de la cultura. México: FCE, 1955. Modernamente, ver BUNGE, Mario, "Culturología». En Las ciencias sociales en discusión: una perspectiva filosófica. Buenos Aires: Editorial Sudamericana, 1999, cap. 5, pp. 242-280.

15 Piaget, Jean. «Introducción: La situación de las ciencias del hombre dentro del sistema de las Ciencias». En Tendencias de la investigación en las ciencias sociales. Madrid: Alianza Editorial, 1973.

16 Sobre el sujeto y «el otro» ver en TouraIne, Alain, Crítica de la modernidad. México: FCE, 2000, pp. 221-225.

17 Campbell, Joseph, El poder del mito. En diálogo con Bill Moyers. Barcelona: Emecé, 1998. Asimismo, ElIADE, Mircea. La prueba del laberinto: conversaciones con ClaudeHenri Rocquet. Madrid: Cristiandad, 1980, p. 204. 
contribuirían a este proceso ${ }^{18}$. En tiempos más recientes los enfoques holísticos reforzarán esta percepción ${ }^{19}$.

Sin embargo, interesa resaltar solo una de esas fuentes que provisionan y abonan a los nuevos paradigmas, y está relacionada con la tecnología. Cuando hacia los años sesenta E. F. Schumacher ${ }^{20}$ postula sus propuestas sobre una tecnología intermedia, con rostro humano, así como el reconocimiento de lo pequeño es hermoso, precisamente por ser a escala humana, deriva en una acerba y sustancial crítica humanista de los sistemas socioproductivos y la economía materialista moderna, que mercantilizan la naturaleza, derrochándola, haciendo uso de ella y más que como auténtico capital natural, como renta dispendiosa. Precisamente al rescatar el modelo de la economía budista, critica la indiferenciación con la cual los sistemas modernos, desarrollan el tratamiento de los recursos naturales renovables; en efecto, mientras la sabiduría budista prescribe que los recursos naturales no renovables, solo deben ser usados en tanto sean indispensables y aun así en este caso, con la mayor meticulosidad; su uso negligente o extravagante es calificado como una expresión de violencia, lo cual se encuentra reñido con el principio de pacificación y simplicidad de la vida, sustento de una forma de existencia social y personal respetuosas y de convivencia con la naturaleza ${ }^{21}$. La lejana Declaración de Estocolmo de 1972 sobre Desarrollo y Medio Humano recoge esta opción o confesionalidad ecológica budista, cuando en su principio 5 prescribe que: «Los recursos no renovables deben emplearse de forma que se evite el peligro de su futuro agotamiento y se asegure que toda la humanidad comparta los beneficios de tal empleo».

18 WiLDBER, Ken. El paradigma holográfico. Una exploración en las fronteras de la ciencia. Barcelona: Editorial Kairos, 1987. Cf. García. Rolando. Sistemas complejos. Conceptos, métodos y fundamentación epistemológica de la investigación interdisciplinaria. Barcelona: Gedisa, 2006.

19 SheldRAKE, Rupert. El renacimiento de la naturaleza. El resurgimiento de la ciencia y de Dios. Barcelona: Paidós, 1994, p. 264

20 Schumacher. Ob. cit. Sobre E. F. Schumacher Society ver < http://www.smallisbeautiful. org/about.html>.

21 Sкоцıмоwsкı, Henry K. «Reexaminando el movimiento ecologista». Revista Medio Ambiente, N 37-38, Lima, 1989; aquí el autor disiente de las perspectivas que ofrecen las tesis de Schumacher. 


\title{
3. Un rastreo de la relación violencia / ambiente (II): la crisis climática consecuencia antropogénica ${ }^{22}$
}

\author{
En buena cuenta desde el moderno discurso integrador y holístico se de- \\ riva una concepción - que se retroalimenta o reencuentra con el pensa- \\ miento tradicional - en el sentido que existe una suerte de dialéctica entre \\ la actuación humana y la naturaleza. En efecto, la famosa teoría de los \\ ańos setenta de la hipótesis Gaia de James Lovelock ${ }^{23}$ parte de concebir \\ que la tierra se comporta como un todo vital y sistémico, "convergiendo" \\ con las lecturas arcaicas o vernaculares (v.g. pachamama, gea) ${ }^{24}$; es decir lo \\ tradicional se reencuentra con lo posmoderno. Ahora bien, recientemente, \\ este autor sostiene que:
}

Gaia, la tierra viva, es vieja y no tan fuerte como hace dos mil millones de años. Se esfuerza por mantener el planeta lo bastante frío para sus millares de formas de vidas contra el implacable aumento del calor del sol. Pero para hacer su tarea todavía más difícil, una de esas formas de vida, los humanos, unos respondones animales tribales con sueños de conquista incluso de otros planetas, han tratado de utilizarla en su único y exclusivo beneficio. Con una insolencia pasmosa, han tomado

22 La Convención Marco de las Naciones Unidas sobre el Cambio Climático, Resolución Legislativa $N^{\circ} 26185$ (1993) señala como objetivo: «Estabilizar las concentraciones de gases de efecto invernadero en la atmósfera a un nivel tal que impida las interferencias antropógenas peligrosas en el sistema climático, para la cual se establecerán razonables sistemas de plazos para la adaptación progresiva de los ecosistemas y las actividades económicas. Y define el cambio climático como aquel «cambio de clima atribuido directa o indirectamente a la actividad humana que altera la composición de la atmósfera mundial y que se suma a la variabilidad natural del clima observada durante períodos de tiempo comparables». Por gases de efecto invernadero (GEI) se entiende aquellos componentes gaseosos de la atmósfera, tanto naturales como antropógenos, que absorben y reemiten radiación infrarroja.

23 Lovelock, J. E. Gaia, una nueva visión de la vida sobre la tierra. Segunda edición. BarceIona: Orbis, 1986. «La hipótesis o Teoría de Gaia es un conjunto de modelos científicos de la biósfera en el cual se postula que la vida fomenta y mantiene unas condiciones adecuadas para sí misma, afectando al entorno. Según la hipótesis de Gaia la atmósfera y la parte superficial del planeta Tierra se comportan como un todo coherente donde la vida, su componente característico, se encarga de autorregular sus condiciones esenciales tales como la temperatura, composición química y salinidad en el caso de los océanos. Gaia se comportaría como un sistema auto-regulador (que tiende al equilibrio)». $<$ http://es.wikipedia.org/wiki/Hip\%C3\%B3tesis_Gaia>.

24 Molyneaux, Brian Leigh. La tierra sagrada. Espíritus del paisaje. Alineamientos antiguos y lugares sagrados. Creación y fertilidad. Ediciones Culturas de la Sabiduría. México: Taschen Benedikt, 2002. 
los depósitos de carbono que Gaia había enterrado para que la atmósfera mantuviera un nivel de oxígeno adecuado para que la atmósfera mantuviera un nivel de oxígeno adecuado y los han quemado. Al hacerlo ha usurpado la autoridad de Gaia y le han impedido que cumpla con su función de mantener el planeta en estado adecuado para la vida. Esos humanos solo pensaban en su propia comodidad e intereses ${ }^{25}$.

Las preocupaciones de Lovelock quedan graficadas por Crispin Tickell ${ }^{26}$ cuando en el prólogo de la referida obra señala:

El mensaje primordial de este libro no es tanto que la propia Gaia esté amenazada (es «una tía muy dura» en palabras de Lynn Margulis), sino más bien que los humanos le estamos infligiendo un dańo cada vez mayor. De todos modos, Gaia cambia, y puede que sea menos fuerte hoy que en el pasado. El calor del sol aumenta continuamente y al final pondrá en peligro la autorregulación de la que depende la vida. Al contemplar el ecosistema global como un todo, el crecimiento de la población humana, la degradación de la Tierra, el agotamiento de los recursos, la acumulación de desechos, la polución de todo tipo, los cambios climáticos, los abusos de la tecnología y la destrucción de la biodiversidad en todas sus formas, constituyen una amenaza sin par a la que las generaciones anteriores no hubieran enfrentado.

En resumen, para Lovelock ${ }^{27}$, estamos ante un suerte de reacción de la naturaleza como consecuencia de la agresión que hemos infligido al sistema planetario. Independientemente del sentido metafórico que pueda conllevar ${ }^{28}$, esta afectación climático-mundial queda, convalidada por diversos estudios científicos. En efecto, recordemos que uno de los «contendores» principales de $\mathrm{Al}$ Gore en la disputa por el premio Príncipe de Asturias fue precisamente el economista británico Sir Nicholas Stern, autor

25 Lovelock J.E. La venganza de la tierra. La teoría de Gaia y el futuro de la humanidad. Barcelona: Editorial Planeta, 2007, p. 211.

$26 \quad$ Ib., pp.14-15

27 Señala Nicolás Sosa al referirse a Lovelock que «el hombre la humanidad, aparece como la «mente de Gaia, figura sugerida por el autor y que invita a deducir que la relación actual de la especie humana con el planeta es como la de la mente de un loco que maltrata su cuerpo y amenaza sus propios órganos vitales; ello permite hablar de la conveniencia de una armonía entre mente y cuerpo en una existencia común y equilibrada. Convivir con Gaia». Ob. cit., p. 277.

28 FOY VAlenCIA, Pierre. «El hombre climático». Prólogo al libro de Germán Vera, Derecho Internacional y cambio climático. Lima: IESC, 2008. < http://www.pucp.edu.pe/climadecambios/index.php?option $=$ com_content\&task $=$ view\&id $=82 \& l t e m i d=39>$. 
del Informe Stern sobre la economía del cambio climático (Stern Review on the Economics of Climate Change $)^{29}$, estudio - por encargo del gobierno del Reino Unido, publicado el 30 de octubre de 2006, con 700 páginas de extensión - da cuenta acerca del impacto del cambio climático y el calentamiento global sobre la economía mundial ${ }^{30}$. También cabe mencionar el Informe Anual del PNUD «La lucha contra el cambio climático: Solidaridad frente a un mundo dividido $»^{31} \mathrm{o}$ «El cambio climático no tiene fronteras. Impacto del cambio climático en la Comunidad Andina». ${ }^{32}$

Como refiere el Informe del PNUD «La mayor parte de las actividades humanas, como la generación de electricidad mediante la combustión de combustibles fósiles, el transporte, el cambio en el uso de la tierra y los procesos industriales, generan emisiones de gases de efecto invernadero» que tal como se señaló, constituyen la fuente generadora del cambio climático ${ }^{33}$. No obstante, existen extremas desigualdades en las huellas ecológicas nacionales ${ }^{34}$ a modo de reflejo de las disparidades en las emisiones per cápita ${ }^{35}$, pues en tanto «los pobres viven en la Tierra dejando una huella ecológica apenas perceptible, soportan el grueso de las consecuencias de la

29 Dicho informe supone un hito histórico al ser el primer estudio encargado por un gobierno no a un climatólogo, sino a un economista.

30 Las claves para la actuación internacional en este tema, según Stern son: a) El negociar de las emisiones; b) Cooperación de la tecnología; c) Acción para reducir la tala de árboles acción a larga escala; d) Adaptación: Los países más pobres son los más vulnerables al cambio del clima.

31 PNUD. Informe sobre Desarrollo Humano 2007-2008. New York: PNUD, 2007.

32 Comunidad Andina de Naciones. El cambio climático no tiene fronteras. Impacto del cambio climático en la Comunidad Andina». Este documento de la Secretaría General de la Comunidad Andina fue coordinado por Carlos Amat y León de la Facultad de Economía de la Universidad del Pacífico. Mayo 2008. PNUD. Ob. cit., p. 55.

34 La huella ecológica es un indicador agregado definido como «el área de territorio ecológicamente productivo (cultivos, pastos, bosques o ecosistemas acuáticos) necesaria para producir los recursos utilizados y para asimilar los residuos producidos por una población dada con un modo de vida específico de forma indefinida». Su objetivo fundamental consiste en evaluar el impacto sobre el planeta de un determinado modo o forma de vida y, consecuentemente, su grado de sostenibilidad. La "huella ecológica» muestra cuánta tierra y agua productiva se ocupan para producir todos los productos que una persona consume, ya sea alimentos, energía, medios de transporte, vestuario y otros bienes materiales o intangibles que sustentan un determinado estilo de vida. ( ) La «huella ecológica» es creación del suizo Mathis Wackernacei, experto en desarrollo comunitario, y del profesor canadiense William Rees de la Universidad de British Columbia, Vancouver < http://www.tierramerica.org/2001/1118/acentos2.shtml > .. PNUD. Ob. cit., p. 59. 
gestión no sostenible de nuestra interdependencia ecológica» ${ }^{36}$. Como refiere Riechman: «Los huracanes tropicales nacen de los tubos de escape de nuestros coches y de las chimeneas de nuestras centrales térmicas». ${ }^{37}$

De otra parte, todo esto implica un desafío en los paradigmas políticos si tenemos en cuenta que:

La naturaleza acumulativa del cambio climático tiene implicancias múltiples y variadas, de las cuales tal vez la más importante sea la falta de coincidencia entre los ciclos del carbono y los ciclos politicos. La actual generación de líderes políticos no puede solucionar el problema del cambio climático, porque para tomar un rumbo de emisiones sostenibles se requieren decenios, no años. Sin embargo, estos líderes sí tienen el poder de abrir oportunidades para las futuras generaciones, o de cerrarles la puerta ${ }^{38}$.

Lo cual nos lleva a reflexionar en el sentido que los sistemas políticos, así como las políticas de Estado deben reorientar sus fundamentos ideológicos en los que se sustentan, para dar paso a nuevos enfoques en un marco de globalidad, interdependencia ecológica y metas estratégicas relativas a la mitigación y adaptación climática, evidentemente sin pretender ser catastrofistas $^{39}$. Para concluir, en definitiva

Como punto de partida para la acción y el liderazgo político, los gobiernos deben reconocer que enfrentan lo que podría constituir la amenaza más grave que haya sufrido la humanidad en toda su historia. La lucha contra el cambio climático exige que los imperativos ecológicos sean una parte medular de la economía. Se trata de un proceso que debe iniciarse en el mundo desarrollado y que no puede esperar. ${ }^{40}$

$36 \quad$ Ib., p. 19.

37 RiechmanN, Jorge. Un mundo vulnerable. Ensayos sobre ecología, ética y tecnología. Madrid: Catarata, 2000, p. 45.

38 Ib., p. 20.

39 Comunidad Andina de Naciones. Ob. cit., p. 37. «La temperatura ha aumentado más que el promedio global y los desastres climáticos se han también duplicado en el último quinquenio. No existe una sola provincia de los países de la CAN que no haya sido afectada al menos un vez por un desastre climático. Para la región, $2{ }^{\circ} \mathrm{C}$ de calentamiento pueden tener impactos de magnitudes catastróficas».

40 PNUD. Ob. cit., p. 31. 


\section{Un rastreo de la relación violencia / ambiente (III): otras afectaciones al ambiente independientemente del cambio climático}

El impacto de las actividades humanas sobre el ambiente ${ }^{41}$ ha sido muy diverso a través de la historia ${ }^{42}$. En particular, en lo que concierne a las afectaciones ambientales contemporáneas se cuenta con diversas elaboraciones y sistematizaciones ${ }^{43}$. A partir de estas se desprenden o evidencian prácticas humanas que podríamos calificar como violentas sobre los entornos humanos - y en consecuencia contra las personas y colectividades adscritas a ellos- pero también afectantes de los ecosistemas como tales ${ }^{44}$ independientemente de la victimidad humana. Al respecto nos permitimos una extensa cita que ilustra esta aseveración y que sintetiza en buena medida la «situación del ambiente y de los recursos naturales» ${ }^{45}$; es decir, un auténtico cuadro de la «violentogénesis» social y ambiental de nuestro país:

[...] 16. En el Perú el deterioro del ambiente y de los recursos naturales es de preocupación por la alta contaminación el agua y deterioro de las cuencas; la mala disposición de los residuos sólidos; las ciudades desordenadas con alta contaminación del aire y baja calidad de vida; la pérdida de los suelos agrícolas por erosión, salinización y pérdida de la fertilidad; la destrucción de al menos 10 millones de hectáreas de bosques y tala ilegal de maderas finas; las 221 especies de la fauna en

41 Ondarza, Raúl. El impacto del hombre sobre la tierra. México: Editorial Trilla, 1998.

42 Ver de David ARNOLD. La naturaleza como problema histórico. El medio, la cultura y la expansión de Europa. México: Fondo de Cultura Económica, 2000. VITALE, Luis. «EI tiempo en la relación sociedad-naturaleza ambiente» Santiago, mayo 1998. Ponencia al Seminario de la Sociedad Geológica de Chile Facultad de Ciencias Físicas y Matemáticas de la Universidad de Chile. < http://mazinger.sisib.uchile.cl/repositorio/lb/filosofia_y_humanidades/vitale/obras/sys/gda/b.pdf > . Ver de MelénDEz Dobles, Silvia. «La historia ambiental: aportes interdisciplinarios y balance crítico desde América Latina». Cuadernos Digitales. Publicación electrónica en historia, archivística y estudios sociales, vol. 7. N 19. Noviembre 2002. Universidad de Costa Rica, Escuela de Historia.

43 Ver del PNUMA. Perspectivas del ambiente mundial 2000 (GEO 2000). Madrid: MundiPrensa, 2000.

44 Aspecto que será desarrollado en el siguiente apartado. Al respecto, por ejemplo, se dice que el planeta «es víctima hoy de una grave adicción al carbono», tal como advirtió el secretario general de la ONU, Ban Ki-Moon, en su mensaje del Día Mundial del Medio Ambiente el 5 de junio de 2008, de modo que la dependencia de la energía basada en el carbono ha producido una acumulación considerable de gases de efecto invernadero en la atmósfera. <http://www.onu.org.pe/Publico/Mensajes/ 20080605medioambiente.aspx >.

45 «Diagnóstico Ambiental del Perú». Preparado por el Grupo de Trabajo Multisectorial Preparación del Ministerio del Ambiente (R.M. N 025-2008-PCM). Lima, febrero, 2008. 
peligro de extinción; la pérdida de cultivos nativos y sus variedades; y la contaminación del aire.

17. El círculo vicioso de la pobreza, que ejerce fuerte presión sobre los recursos naturales y el ambiente, ha llevado a que los procesos de deterioro del ambiente y de los recursos actualmente sean alarmantes y también afectan a los pobres en dos sentidos: reducen los recursos naturales indispensables para sus actividades productivas (suelos, agua, bosques, fauna, pesca, etcétera), y tienen un fuerte impacto sobre su salud y estabilidad social por la contaminación y la emigración hacia las ciudades y otras regiones, como la Amazonía.

18. El deterioro de la calidad del agua es uno de los problemas más graves del país y es un impedimento para lograr el uso eficiente del recurso, y compromete el abastecimiento en calidad, en cantidad y en forma sostenible. Las causas principales están en la contaminación industrial; la falta de tratamiento de las aguas servidas; producción de cocaína; el uso indiscriminado de agroquímicos; y el deterioro de las cuencas de los ríos por actividades antrópicas.

19. Los problemas de contaminación del aire extradomiciliaria están concentrados en las grandes ciudades, en especial Lima-Callao, y en lugares con industrias contaminantes, especialmente mineras y pesqueras. En las ciudades la causa principal de la contaminación está en el parque automotor, en incremento rápido, constituido en gran parte por vehículos antiguos y sin una regulación adecuada tanto de los vehículos como del tráfico. Una contaminación importante y nociva es el contenido de azufre en el diesel, que supera las 7000 partes por millón (ppm), cuando debería estar en menos de 500 ppm. La contaminación del aire intradomiciliaria es un problema de salud ambiental en las zonas rurales debido al uso de ciertos combustibles (leña, bosta, plásticos) para cocinar y calentar casas, pero con poca o ninguna ventilación.

20. Los suelos de aptitud agropecuaria son el recurso más amenazado por procesos de deterioro, en especial la salinización en la costa, la erosión paulatina en la sierra y la pérdida de fertilidad en la Amazonía. Un total de 8 millones de hectáreas están clasificadas como severamente erosionadas y 31 millones de moderadamente erosionadas. El deterioro de los suelos afecta la productividad agrícola y ganadera, por disminuir gradual o, en algunos casos, violentamente (huaycos, aluviones y erosión fluvial), la producción en las zonas rurales, y, como efecto, contrae la economía de las poblaciones rurales. No existe en el país ninguna institución dedicada directamente al manejo de los escasos suelos agrícolas. 
21. Cerca del $70 \%$ de la población peruana vive en ambientes urbanos, y las ciudades crecen en forma acelerada y desorganizada, con una serie de problemas ambientales de tremendo impacto sobre los pobladores y el entorno. Se está produciendo un deterioro creciente de la calidad y disponibilidad del agua, por la falta de gestión adecuada de las fuentes de abastecimiento y la distribución y el mantenimiento de los sistemas. El deterioro grave de la calidad del aire por gases, olores, y quema de residuos, entre otros, es creciente. Existe un alto déficit de áreas verdes y recreativas para la población.

22. La diversidad biológica, a pesar de su tremenda importancia, es afectada en el país por diversos procesos, que van reduciendo la disponibilidad de recursos genéticos, especies y ecosistemas estables. La tala de bosques es un proceso de enormes consecuencias ambientales, económicas y sociales. La degradación de ecosistemas importantes es grave como también la amenaza de extinción de especies de la flora y de la fauna. Las consecuencias sobre las poblaciones rurales son muy diversas, y van desde la reducción de la seguridad alimentaria a mayor empobrecimiento por la reducción de recursos.

23. La extinción de grupos y culturas aborígenes es un proceso histórico y continuo, que ha llegado a una situación crítica en los tiempos modernos. Entre 1950 y 1997 se han extinguido 11 grupos aborígenes de la Amazonía (resígaro, andoque, panobo, shetebo, angotero, omagua, andoa, aguano, cholón, munichi y taushiro) y de los 42 remanentes 18 de ellos están en peligro de extinción por tener menos de 225 personas. Es necesario considerar que en este proceso se pierde una enorme cantidad de conocimientos tradicionales acumulados durante milenios.

Para solo referirnos a un ejemplo sensible, la extinción de especies, en realidad representa una intervención o actuación profundamente violenta sobre la naturaleza y su equilibro. Como consta en el «Listado Rojo de Especies Amenazadas 2006", elaborado por la UICN, los humanos son directa o indirectamente, la causa principal de la rápida disminución de las especies ${ }^{46}$.

46 La Unión Internacional de Conservación de la Naturaleza (UICN) entregó su publicación anual del «Listado Rojo de Especies Amenazadas» en marzo de 2006. En ella se evalúan más de 40 mil especies de animales y plantas, demostrando que globalmente el número de especies amenazadas se ha incrementado en más de $50 \%$ durante la última década. Casi 600 nuevas especies se identificaron ahora como amenazadas y se declara oficialmente extinguidas a más de 800 especies. Este último «Listado Rojo» reconoce que los humanos, sea directa o indirectamente, son la causa principal de la rápida disminución de las especies. El calentamiento global, la caza vedada, la pérdida de hábitat, 
En este contexto podemos singularizar de manera ilustrativa — sin ser excluyentes - tres fenómenos altamente violentos respecto el ambiente:

a. Las actividades bélicas ${ }^{47}$. Por ejemplo la organización BirdLife International presentó un informe a la ONU, al Consejo de Seguridad y a Bagdad en el que exponía las principales amenazas que la guerra representa para el entorno ${ }^{48}$ :

- Destrucción física y alteración de la fauna silvestre y hábitats naturales debido al uso de armas.

- Contaminación tóxica de la fauna y de los hábitats debido a los vertidos de petróleo y a la combustión de pozos de combustible.

- Contaminación radiológica, química o biotóxica por bombardeos y uso de armas de destrucción masiva.

- Destrucción física de fauna y hábitats debido al aumento de presión humana causada por los movimientos masivos de personas que huyen de la guerra. Cientos de miles de refugiados necesitan grandes cantidades de agua y leña, en un hábitat donde ambos recursos son escasos.

- Incendios en humedales.

- Aplastamiento mecánico de vehículos sobre el desierto, que puede resultar dañado por décadas.

- Extinción de especies endémicas.

b. Las actividades biotecnológicas modernas. La literatura y reflexión sobre el tema es exhaustiva. Nos limitamos a señalar que como parte de las megatendencias en la seguridad internacional, cobran dramática vigencia

las prácticas de pesca no sustentables están teniendo impactos significativos sobre las especies tales como el oso polar, el hipopótamo pigmeo, la gacela «dama», el tiburón ángel. En 2006, todos estos emblemáticos animales han tenido que ser reclasificados en categorías más próximas a la extinción. Organismos menos conocidos, incluyendo muchas especies de anfibios y peces de agua dulce se han reducido dramáticamente en número. <http://www.induambiental.cl/1615/propertyvalue-37260.html\#h2_3>.

47 Ver de RusseLL, Edmund. War and Nature. Fighting Human and Insects with Chemicals from World War I to Silent Spring. Cambridge: Cambridge University Press, 2001.

48 «El medio ambiente, otra víctima de la guerra» < http://www.ambientum.com/revista/ 2003 03/guerra.htm > . Al respecto, la Asamblea General de Naciones Unidas declaró el seis de noviembre de 2002 como Día internacional para prevenir la explotación del medio ambiente en los conflictos armados y en las guerras. 
la cuestión del desarrollo de las amenaza no tradicionales en el campo estratégico, aspectos como las armas de destrucción masiva, entre la cuales se encuentran las armas biológicas y las implicancias ambientales que ello conlleva ${ }^{49}$. En donde la guerra biológica, se entiende definida como la manipulación de organismos vivos con fines destructivos.

c. Las amenazas del bioterrorismo. Asociado o a lo anterior, tiene su propia caracterización e impactación ambiental. Así, Alvin Toffler nos advierte acerca de los fermentos antidemocráticos que se pueden incubar desde los fundamentalismos ecológicos (ecoteocracias) y las implicancias sociales y ambientales (ecoterrorismo) ${ }^{50}$.

\section{Una interrogante epistemológica ¿̨se puede hablar de violencia contra la naturaleza? (¿homini lupus natura?) $)^{51}$}

Con gran sentido antropológico Fernando Silva Santisteban nos dice que el hombre se ha convertido en un depredador puesto que debido a sus necesidades biológicas «satisface también a través de la depredación y la violencia diversos impulsos individuales y colectivos que lo han convertido en el más grande agresor, incluso de la naturaleza» ${ }^{52}$. Al reafirmar la condición del hombre como depredador, continúa Silva Santisteban, el hombre a diferencia del animal, mediante la tecnología y el conocimiento adapta el medio ambiente a sus necesidades, habiendo de esta manera poblado todos los climas del planeta, expandido por todos los continentes y desarrollado su población y cultura en un inusitado crecimiento exponencial, pero, «simultáneamente, ha agredido al medio ambiente en una escala aterradora que compromete la propia supervivencia de su especie» ${ }^{53}$.

49 Agozino, Adalberto. Megatendencias en la seguridad internacional. Buenos Aires. Editorial Ábaco de Rodolfo Desalma, 1998.

50 Toffler, Alvin. El cambio del poder. Barcelona: Plaza \& Janés, 1994. Ver también en $<$ http://www.mty.itesm.mx/dhcs/deptos/ri/ri95-801/lecturas/lec069.html>.

51 ¿Hemos heredado de nuestros ancestros algo más que el ansia de poder y una violenta territorialidad? Ver de Frans de WAAL. El mono que llevamos adentro. Barcelona: Tusquets editores, 2007.

52 Silva Santisteban, Fernando. El primate responsable. Antropobiología de la conducta. Lima: Fondo Editorial del Congreso del Perú, 2005, pp. 114-115.

53 Ob. cit., pp. 214-215. 
En los años noventa se expidió un Informe de la Comisión del Senado de la República sobre Violencia y Pacificación, el cual excluía toda referencia a la violencia que pudiera provenir de la naturaleza o la que el hombre dirigiera hacia ella, siempre que carezcan de consecuencias sociales relevantes. Su definición de violencia, comprendida como social, ${ }^{54}$ fue analizada por Mac Gregor y Rubio cuando buscaban establecer criterios metodológicos para su conceptualización. Sin ser el centro de su interés la discusión sobre violencia / naturaleza, colateralmente la abordan y al criticar la definición de la Comisión que «No toma en cuenta la violencia ejercida por la naturaleza sobre el hombre y viceversa, en tanto carezcan de consecuencias sociales relevantes. Tampoco la violencia que constituye instinto innato o común al resto de animales». $\mathrm{Al}$ respecto dicen los autores que «si los desastres naturales conllevan actitudes negativas de unos seres humanos frente a otros, estas formarán parte de la causa eficiente de la violencia pero no de la violencia misma» (v.g. si un terremoto genera pillaje la violencia estará no en el sismo sino en las conductas de los protagonistas y en la omisión del control de parte de las autoridades). También critican en el sentido que «las consecuencias sociales relevantes de la violencia contra la naturaleza pertenecen al ámbito de las relaciones entre seres humanos, pues los que destruyen la naturaleza en forma dolosa o culposas perjudican al resto. El daño ecológico, que es a lo que aquí se hace referencia, no parece ser un fenómeno prioritariamente aplicable a la relación del hombre con la naturaleza, sino a la relación entre humanos, dentro de la cual la preservación de la naturaleza resulta indispensable».

En el mismo estudio los mencionados autores elaborarán sus propias definiciones con el objeto de buscar conceptos que ayuden a entender los rostros de la violencia, de tal modo que:

Violencia: ${ }^{55}$

Es una presión de naturaleza física, biológica o espiritual, ejercitada directa o indirectamente por el ser humano sobre el ser humano que,

54 Mac Gregor, Rubio y Vega-Centeno. Ob. cit., p. 23. "Violencia social es la que expresa, en diversos grados y múltiples formas, entre los individuos y grupos sociales, producto de circunstancias sociales que, al permanecer y reproducirse históricamente, estructuran y caracterizan a una determinada forma de organización social que mediatiza la potencial realización de sus miembros». 
pasado cierto umbral, disminuye o anula su potencial de realización, tanto individual, como colectivos, dentro de la sociedad de que se trate.

Violencia estructural: ${ }^{56}$

Violencia que ocurre al ser humano desde y en las estructuras de la sociedad. Es decir, la violencia estructural es distinta de las otras formas de violencia por su causa eficiente. En la violencia estructural la presión al ser humano emerge de las formas cómo se relacionan los seres humanos entre sí, y de las reglas (aceptadas o no) que regulan dichas relaciones.

Violencia institucional: ${ }^{57}$

Aquella especie de violencia estructural aceptada por las personas, por hallarse formal o realmente encarnada por las instituciones y tener consideración aceptable (formal o materialmente). [...] El Derecho (así discrepemos del contenido de las leyes) será una forma de violencia institucional cuando produzca efectos negativos.

Podemos concluir que las percepciones revisadas acerca de la relación violencia / naturaleza, cuando esta es tomada en cuenta, solo tiene significancia en la medida en que dicha violencia sea generada por los seres humanos y afecte socialmente al resto ${ }^{58}$. Estamos sin duda ante una concepción eminentemente "antropocéntrica», que acaso por la época en que se formuló no podía considerar lo que hoy en día entendemos como las implicancias o factores antropogénicos que actúan o inciden sobre la naturaleza. En realidad el propio concepto de naturaleza cada vez más tiende a imbricarse con el de artificialeza en la medida en que globalmente hay una incidencia antropógena sobre todo el planeta que viene acumulándose y adquiriendo dimensiones inclusive catastróficas; cabría decir que el impacto cultural

\footnotetext{
lb., p. 50.

lb., p. 57.

58 El resumen del Informe mundial sobre la violencia y la salud de la OMS del año 2002, utiliza un interesante modelo ecológico para entender las raíces de la violencia. «No existe un factor que, por sí solo, explique por qué una persona se comporta de manera violenta y otra no lo hace. La violencia es un problema complejo, enraizado en la interacción de muchos factores biológicos, sociales, culturales, económicos y políticos. Algunos factores de riesgo pueden ser privativos de un tipo determinado de violencia, pero es más frecuente que los diversos tipos de violencia compartan varios factores de riesgo. Además de esclarecer las causas de la violencia y sus complejas interacciones, el modelo ecológico también indica lo que es preciso hacer en los diversos niveles para prevenirla", p. 20.
} 
tecnosférico es tal que todo el sistema climático ${ }^{59}$ de la Tierra tiende a ser afectado significativamente por la acción humana. Al respecto Riechmann en referencia al desvastador huracán Mitch del año 1998 y el cambio climático, como fenómenos relacionados por vínculos causales señala ${ }^{60}$ :

En épocas anteriores de la historia hubiera sido considerado una catástrofe natural ajena por completo a la intervención humana, a finales del siglo XX sabemos que tiene que ver con los cambios en la composición química de la atmósfera que resultan de la actividad de las sociedades industriales. Nos hemos convertido en una fuerza geológica planetaria, capaz de influir decisivamente en condiciones que hace que se produzcan «catástrofes» naturales.

En efecto, si nos ponemos a pensar que la denominada Chindia (China e India), tiene dos tercios de la población mundial y que gran parte de ella depende de los servicios ambientales hídricos que les proporciona el sistema Himalayo ${ }^{61}$, y que debido al fenómeno de deglaciación se va a desencadenar el denominado «stress hídrico" por un lado y por el otro, el elevamiento de los niveles del mar asociado al incremento de los fenómenos atmosféricos.

Ahora bien, si tomamos en cuenta no solo el referente climático en términos globales sino en general las otras actuaciones humanas que deterioran el ambiente sean igualmente a escala global o no como la destrucción de las especies y de la biodiversidad surge la interrogante ¿estamos ante una situación de violencia contra el ambiente? Evidentemente que desde las construcciones conceptuales más convencionales, se diría que no siempre que ello no involucre una incidencia mediatizada de afectación a los valores humanos o sociales, más la violencia sobre la naturaleza en sí no estaría incluida. Desde nuestra perspectiva y retomando los enfoques contemporáneos de la ecología política ${ }^{62}$ y las concepciones holísticas, por el contrario consideramos que sí se trata de una situación de violencia contra

59 Según la Convención Marco de las Naciones Unidas sobre el Cambio Climático: Por «sistema climático» se entiende la totalidad de la atmósfera, la hidrósfera, la biósfera y la geósfera, y sus interacciones.

60 Riechmann. Ob. cit., p. 47.

61 Gore, Albert. Una verdad incómoda: la crisis planetaria del calentamiento global y cómo afrontarla. Barcelona: Gedisa, 2007.

62 Ver: Dobson, Andrew. Pensamiento político verde. Madrid: Trotta - Serie medio ambiente, 1999. 
la naturaleza; es decir, de orden antropogénica, que indudablemente también afecta los valores humanos y sociales. Como señala Miriam Alfie ${ }^{63}$ :

La violencia que el hombre ejerce sobre su medio ambiente se conforma en todos los ámbitos del planeta, no solo en los recursos renovables y no renovables, ni en las distintas especies animales y vegetales amenazadas. La inminencia de una crisis ecológica del planeta no es algo remoto, pues de no revertirse las tendencias actuales la situación de alto riesgo se presentaría en dos o tres décadas.

$\mathrm{Al}$ respecto, Edgard Goldsmith ${ }^{64}$, director del semanario británico The Ecologist y vicepresidente de la Asociación de Ecologistas de Europa, al referirse a la antes mencionada hipótesis Gaia de Lovelock, emplea una terminología un tanto especializada expresada en la siguiente secuencia que luego explicaremos:

- La ecósfera es una organización jerárquica de los sistemas naturales.

- Los sistemas naturales son homeotélicos ${ }^{65}$ para Gaia.

- Cuando el control gaiano se debilita, la conducta se vuelve heterotélica ${ }^{66}$.

- Los sistemas naturales solo pueden tener una conducta homeotélica dentro de su margen de tolerancia.

- La conducta de un sistema natural está controlada homeoárqicamente ${ }^{67}$ por una jerarquía de sistemas más amplios de los que forma parte.

63 AlfiE, Miriam. «Violencia ecológica vs. desarrollo sustentable». Violencia y derechoshumanos, $\mathrm{N}^{\circ}$ 63, julio-agosto 1994 < http://www.elcotidianoenlinea.com.mx/doc/6310. doc $>$.

64 Goldsmith, Edgard. El tao de la ecología. Una visión ecológica del mundo. Barcelona: Icaria, 1999.

65 Los sistemas naturales solo pueden cooperar si tienen el propósito de conseguir un objetivo común, sin el cual el propio término cooperación carecería de significado; como partes diferenciadas de la jerarquía galana, comparten el mismo objetivo común de mantener su estabilidad u orden crítico (homeo: igual; telos: fin).

66 La conducta homeotélica es una conducta normal que cumple con su finalidad filogenética y ontogenética: mantener el orden crítico de la ecósfera. La conducta heterotélica (hetero: diferente; telos: fin) es una conducta mal enfocada, que satisface hasta cierto punto las necesidades del individuo, pero no las de la jerarquía galana.

67 La ecósfera al igual que todos sus susbsistemas constituyentes está dotada del mecanismo de control necesario para controlar y coordinar la conducta homeotélica de las partes que la constituyen. Ese control lo denomina Goldsmith homeárquico (homeo: igual, archos: gobierno). 
- Cuando el entorno difiere de su situación óptima, aumentan los desajustes biológicos ${ }^{68}$.

- En la medida en que el entorno se diferencia de lo óptimo, aumenta el desajuste social.

- En la medida en que el entorno se diferencia de lo óptimo, aumenta el desajuste cognitivo ${ }^{69}$.

Si quisiéramos hacer una síntesis de tales planteamientos, significaría que las actuaciones humanas contemporáneas han desencadenado desajustes y agresiones al equilibrio de los ecosistemas como consecuencia de los modelos de intervención económico y tecnológico, con prescindencia axiológica de las dinámicas y leyes de la naturaleza. $\mathrm{Al}$ respecto desde muchos escenarios, hoy en día surgen voces que postulan o retoman conceptos aparentemente vernaculares o tradicionales como los de «dignidad de la naturaleza $»^{70} \mathrm{o}$ «dignidad de la tierra $»^{71}$, inclusive se alude a la dimensión moral del ambiente natural ${ }^{72}$. Desde una perspectiva de Ecología Política podría aludirse al «antropocentrismo fuerte» en el sentido que la intervención humana sobre el entorno se legitima en la medida que se identifica al hombre y su cultura como el centro y los elementos de la naturaleza estarían a su disposición a partir de sus capacidades tecnológicas. Por el contrario

68 Como refiere Goldsmith, las drásticas agresiones a la biósfera causadas por el progreso económico están alertando el entorno de los seres vivos que constituyen la jerarquía galana.

69 Hoy no tenemos medios para comprender nuestra relación con el mundo que hemos creado [...] No solo nos fallan los sentidos y las facultades intuitivas ante el vigoroso nuevo mundo que está creando el crecimiento económico; nuestros verdaderos instintos también dejan de servirnos como guía para una conducta adaptable [...] Un ejemplo típico es nuestra instintiva agresividad. En una sociedad vernácula, al igual que las demás formas de competencia, está muy ritualizada y sirve para fines sociales, incluso cósmicos. Su destructividad también queda limitada porque la tecnología vernácula está bajo control social, lo cual significa que en las guerras se lucha con armas tradicionales, que no son específicamente letales. [...] Todo esto varía drásticamente con el crecimiento económico cuando la destrucción social y cultural aunada nos priva de los medios de controlar nuestra agresión y de evitar la propagación de los más letales y destructivos armamentos (p. 240).

70 García Gomez-Heras, J.Ma . La dignidad de la naturaleza. Ensayos sobre ética y filosofía del medio ambiente. Granada: Ecorama, 2000.

71 Boff, Leonard. La dignidad de la tierra. Ecología, mundialización, espiritualidad. La emergencia de un nuevo paradigma. Madrid: Trotta, 2000.

72 Ver de Velayos, Carmen. La dimensión moral del ambiente natural ¿necesitamos una nueva ética? Granada: Ecorama, 1996. 
desde un enfoque de «antropocentrismo débil» según Bellver Capella ${ }^{73}$ (o antropocentrismo sabio en los términos de Sosa ${ }^{74}$ ), el «ser humano admite su centralidad pero puede poner límites y orientar sus preferencias, estableciendo deberes hacia objetos no humanos» ${ }^{75}$, en buena cuenta "la respuesta de la ecología política no consiste en sacralizar la naturaleza sino en reivindicar cambio de paradigmas: de la razón tecnocrática moderna, que se cree a sí misma autosuficiente para ordenar el mundo y la sociedad, a la razón práctica, que es consciente de sus límites y de la necesidad de encontrar su propio sentido a través de la comunicación interpersonal y de la observación de la naturaleza» ${ }^{76}$.

En conclusión, como consecuencia de la nueva percepción y de los paradigmas de la relación hombre entorno, es plenamente razonable en perspectiva crítica aludir a una violencia contra el ambiente y los entornos, quedando siempre en discusión el carácter axiológico valorativo de tales posturas. Sin incurrir en posturas extremas como las de la «ecología profunda ${ }^{77}$, es factible razonar desde una concepción de lo que el pensador y ex ministro francés de educación Luc Ferry plantea como "La ecología democrática» a modo de objeción a los enfoques un tanto ecofundamentalistas y por consiguiente señala: «Reconciliada con el Estado, que le da ministros, con la democracia, la ecología se integra por fin al mercado, que se adapta con toda naturalidad a las nuevas exigencias de los consumidores ${ }^{78}$.

En este contexto surge la preocupación de cómo conexar esta relación violencia / ambiente con el sistema jurídico. Es decir los procesos de juridificación doctrinal, normativa, jurisprudencial o paccional de la violencia contra el ambiente. ¿Es del daño ambiental una expresión de esta juridificación de la violencia ambiental?

73 Bellver Capella, Vicente. «Las ecofilosofías». En Ballesteros y Pérez Adán. Ob. cit., pp. 251-269.

74 SOSA. Ob. cit., p. 287 y ss.

75 Bellver Capella. Ob. cit., p. 251.

76 Refiere Bellver Capella, citando a Ballesteros, Ib., p. 261

77 FerRY, Luc. El nuevo orden ecológico. El árbol, el animal y el hombre. Barcelona: Tusquets, 1994, p. 109 y ss.

78 Ob. cit., pp. $188-213$ y p. 212. 


\section{6. ¿Cómo intervienen los sistemas jurídicos en esta relación violencia / ambiente?}

El escenario relacional al respecto es complejo. En nuestro trabajo sobre «En busca del Derecho Ambiental (I), sentamos las bases conceptuales e histórica para entender los procesos por los cuales surge el Derecho Ambiental en una perspectiva sistémica ${ }^{79}$. Acaso unos de los temas que se presta mayormente para aproximarse a estas relaciones sería la dimensión penal-criminológica ${ }^{80}$, bajo la limitación antropocéntrica en el sentido que la protección de los valores o bienes jurídicos tutelados tienen como sustento último la vida humana y los medios que permiten su realización o despliegue en sus diferentes dimensiones: personales, biológicas, culturales, sociales, económicas y por qué no decirlo, «sistémicas». Apelando al enfoque anteriormente señalado acerca del antropocentrismo débil, es decir que sin cuestionar la centralidad del ser humano (tema debatible desde los anchurosos territorios de la ética ecológica), es factible afirmar el imperativo que los sistemas jurídicos protejan valores ambientales o entornos, más aun cuando se encuentran amenazados o afectados de modo violenta (el ambiente como víctima) independientemente de la tutela instrumental de los valores humanos. Nuestro Tribunal Constitucional de alguna manera ha reiterado esta suerte de antropocentrismo débil al considerar el contenido esencial del derecho al medio ambiente equilibrado en el sentido que: «El contenido del derecho fundamental a un medio ambiente equilibrado y adecuado para el desarrollo de la persona humana está determinado por los siguientes elementos: a) el derecho a gozar de ese medio ambiente y b) el derecho a que ese medio ambiente, se preserve (FJ 20-2)» ${ }^{81}$.

79 For ValenCIA, Pierre. «En busca del Derecho Ambiental (I)». En Derecho y ambiente. Aproximaciones y estimativas. For, Pierre (editor). Lima: Fondo Editorial de la PUCP, 1997, pp. 35-170.

80 Caro, Carlos. Derecho penal del ambiente. Delitos y técnicas de tipificación. Gráfica Horizontes, Lima, 1999. Ver de For ValenCIA, Pierre. a) Criminalidad y Derecho Penal Ambiental. Estudio preliminar y selección de textos especializados 1 (Antología). Lima: Universidad de Lima, 1994; b) «Consideraciones sobre criminalidad ambiental y empresa». Gaceta Jurídica. 1997 Tomo 43, p. 63-A / 69-A, c) «Aproximaciones y estimativas al estudio de la criminalidad y el Derecho Penal Ambiental Peruano». Revista Derecho de la PUCP N ${ }^{\circ} 46$, diciembre de 1992, pp. 257-274.

81 Tribunal Constitucional. Resolución N 04223-2006-AA/TC 05/09/2007. Fecha de publicación NEXTEL Caso. 
Una aproximación jurisprudencial constitucional en la dirección de protección de la naturaleza nos la brinda el Tribunal Constitucional cuando refiere que ${ }^{82}$ :

26. A juicio de este Colegiado, el Estado tiene el deber de asegurar que las personas no actúen con violencia frente a otras personas, ni con crueldad contra los animales, lo cual tiene un fundamento jurídico y ético. Desde la perspectiva jurídica, cabe señalar que dicho deber, se basa, en primer lugar, en el derecho fundamental al bienestar y a la tranquilidad de las personas (artículo 2, inciso 1 de la Constitución) que sí se sienten afectadas en sus sentimientos al presenciar ya sea directamente o al tomar noticia de la existencia de la realización de tratos crueles contra los animales.

En segundo lugar, este deber estatal se justifica en la responsabilidad jurídica que tienen las personas con los animales. Sobre esto, y en aplicación del método comparativo como quinto método de interpretación constitucional, es pertinente reproducir lo que el Tribunal Federal Alemán ha sostenido al respecto, en relación con el derecho al libre desarrollo de la persona contemplado en el artículo $2^{\circ}-1$ de la Ley Fundamental de Bonn:

La finalidad de la ley de protección a los animales es la de garantizarles que se encuentren bien, con base en la responsabilidad que tienen los seres humanos por los animales, al ser considerados como sus semejantes. A ninguna persona le está permitido someter a un animal, sin motivo justo, a dolor, sufrimiento o daño [...]. Al objetivo de una protección a los animales, fundada en la ética [...], sirve también la reglamentación $[\ldots]^{83}$.

82 Sentencia del Tribunal Constitucional. ASUNTO: Demanda de inconstitucionalidad interpuesta por don Luis Alejandro Lobatón Donayre y más de cinco mil ciudadanos, contra el artículo 54 del Decreto Legislativo 776, Ley de Tributación Municipal, modificada por el Decreto Legislativo 952, en cuanto establece que el impuesto a los espectáculos públicos no deportivos grava el monto que se abona por concepto de ingreso a espectáculos públicos no deportivos en locales y parques cerrados con excepción de los espectáculos en vivo de teatro, zarzuelas, conciertos de música clásica, ópera, opereta, ballet, circo y folclore nacional, calificados como culturales por el Instituto Nacional de Cultura <http://www.tc.gob.pe/jurisprudencia/2005/000422004-Al.html\#_ftn28>.

83 En Alemania protección de animales con rango constitucional. Alemania se constituye en el primer país de la Unión Europea en incluir la protección de los animales como un objetivo de Estado, en su Constitución. Es así como el artículo 20a indicará en lo sucesivo que el Estado, asumiendo su responsabilidad ante las generaciones venideras, protege «las bases naturales de existencia y a los animales». A partir de la modificación 
En la discusión doctrinaria es importante revisar la experiencia que se desprende del famoso caso por el cual las empresas de Walt Disney pretendían construir un complejo turístico y de diversión en el valle silvestre Mineral King. A lo cual se opuso el poderosísimo Sierra Club, apoyado por el posteriormente célebre abogado Christopher Stone quien planteó que el parque sea considerado como una persona jurídica, postulando al respecto una tesis a favor de los derechos de los objetos de la naturaleza y que cuyo resultado ante la Corte Suprema de los nueve jueces, fue cuatro votos en contra, dos abstenciones y tres votos a favor ${ }^{84}$.

La Ley General del Ambiente ${ }^{85}$ no emplea el término violencia; mas al referirse al daño ambiental alude, suponemos que metafóricamente, al sufrimiento.

Artículo 142.- De la responsabilidad por daños ambientales

142.2 Se denomina daño ambiental a todo menoscabo material que sufre el ambiente y/o alguno de sus componentes, que puede ser causado contraviniendo o no disposición jurídica, y que genera efectos negativos actuales o potenciales.

A su turno la Ley Forestal y de Fauna Silvestre, Ley 27308 desliza una consideración en términos de indemnizar a los bosques por los servicios ambientales ${ }^{86}$ :

Artículo 35.- Indemnización por los servicios ambientales de los bosques $[\ldots]$

constitucional, la protección de los animales adquiriría un nuevo peso de modo que en el futuro los tribunales tendrán que sopesar entre la defensa de los animales y otros valores constitucionales, como la libertad de investigación o la religiosa

<http://www.dw-weblog.com/dw/article/0,2144,524839,00.html al 100608 >.

84 FerRY. Ob. cit., pp.19-21. Ver directamente el trabajo de Stone, Christopher. Should trees have standing? And Other Essays on Law, Morals and the Environment. New York: Oceana Publications, 1996.

85 Ver de For ValenCIA, Pierre. «El Derecho Ambiental peruano y la Ley General del Ambiente, Ley $\mathrm{N}^{\circ}$ 28611. Un estado de la cuestión». En Ensayos jurídicos contemporáneos. Testimonio de una huella académica. Lima: Editorial Pacífico, 2006.

86 Artículo 2.- Definición de recursos forestales, de fauna silvestre y de servicios ambientales. (..)

2.3 Son servicios ambientales del bosque los que tienen por objeto la protección del suelo, regulación del agua, conservación de la diversidad biológica, conservación de ecosistemas y de la belleza escénica, absorción de dióxido de carbono y en general el mantenimiento de los procesos ecológicos esenciales. 
35.1 El Estado implementará a partir del año 2005 mecanismos de indemnización por los efectos de la contaminación producida por el consumo de combustibles fósiles, que serán destinados al financiamiento de actividades de conservación, rehabilitación de áreas naturales e investigación forestal y de fauna silvestre.

No menos sugerente en esta perspectiva de juridificación tutelar y por ende de protección ante la agresión, violencia o daño a los valores ambientales no humanos o al menos no directamente expresados como tales, es la Ley 27265 - Ley de Protección a los Animales Domésticos y a los Animales Silvestres mantenidos en cautiverio.

Artículo 2.- Objetivos de la Ley

Son objetivos de la presente Ley:

a) Erradicar y prevenir todo maltrato y actos de crueldad con los animales, evitándoles sufrimiento innecesario.

b) Fomentar el respeto a la vida y derechos de los animales a través de la educación.

Artículo 3.- Obligaciones de los dueños o encargados de los animales Son obligaciones de los dueños o encargados de los animales:

a) Velar por su alimentación, salud y condiciones de vida adecuadas, según su especie.

b) No causarles, ni permitir que se les causen, sufrimientos innecesarios.

Artículo 4.- Obligación de autoridades y de instituciones protectoras de animales

4.1 El Estado y las instituciones protectoras de animales debidamente reconocidas quedan obligados a velar por el buen trato, salud y respeto a la vida y derechos a los animales.

En resumen si bien no podemos pasar revista a toda la normativa concernida de una u otra forma, consideramos que la protección jurídica respecto la violencia inferida contra la naturaleza y los valores ambientales se encuentra desarrollada in cresciendo en nuestro sistema legal y en los sistemas jurídicos comparados. Demás está referirse al ámbito del soft law (pre jurídico) en donde encontramos documentos realmente interesantes, tales como La Carta Mundial de la Naturaleza de la ONU de $1982^{87}$, no suscrita

87 <http://www.mbigua.org.ar/uploads/File/CartaMundialNaturaleza.pdf>. 
por el Perú debido a la miopía diplomática de entonces), La Declaración Universal de los Derechos de los Animales de la UNESCO $(1978)^{88}$, la Declaración de los Grandes Simios ${ }^{89}$, entre otros.

Para concluir este apartado que en realidad constituye más el punto de partida para el ulterior desarrollo y reflexión crítica sobre los alcances y limitaciones del sistema jurídico ambiental, no podemos dejar de enfatizar el indispensable reforzamiento tutelar jurídico y extrajurídico que se requiere de valores esenciales tales como el agua ${ }^{90}$ y la diversidad biológica, fuentes de conflictos actuales y exponencialmente agravados, así como de amenaza y alteración a su existencia como tal. El reputado científico Masaru Eramoto, nos ha demostrado sus experiencias acerca del multivalor del agua, pero también sobre los efectos que la violencia puede ejercer sobre el agua; sine embargo, lo más relevante - acaso fantástico- es el efecto positivo de la la no violencia sobre el agua y sus consecuencias e implicancias favorables para la naturalezas y para los humanos. ¡Cómo es posible que la soberbia de los sistemas jurídicos y de los juristas (lamentablemente para muchas situaciones no siempre cuentan con enfoques o visiones holísticas y más bien si con deformaciones biocéntricas y especistas), podrían estar rezagados o ajenos a estas realidades.

\section{La violencia de los conflictos socioambientales}

Otro aspecto que se articula a la relación sistema jurídico/violencia/ambiente es el de los denominados conflictos socioambientales ${ }^{11}$. Es violencia asociad

88 Incluso en su artículo 12. señala: a) Todo acto que implique la muerte de un gran número de animales salvajes es un genocidio, es decir, un crimen contra la especie. b) La contaminación y la destrucción del ambiente natural conducen al genocidio < http:// www.filosofia.org/cod/c1977ani.htm>.

89 The Great Ape Project: Equality Beyond Humanity apareció originalmente en 1993, en edición británica a cargo de Singer, Peter y Paola CavalierI (editores). London: Fourth Estate. Cfr. El Proyecto Gran Simio: la igualdad más allá de la humanidad. Madrid: Trotta, 1998 < http://www.revistadefilosofia.com/11-07.pdf>.

90 Ver de Barlow, Maude. El oro azul. La crisis mundial del agua y la reificación de los recursos hídricos del planeta Edición revisada. Primavera 2001. La autora es Presidenta Nacional del Council of Canadians (Consejo de los Canadienses), Presidenta del Comité sobre mundialización del agua del IFG.

91 Según Alfonso Martínez González, citado por Martinez Gonzalez, Alfonso. Métodos alternativos en manejo de conflictos. Aplicaciones en materia ambiental. México: SEMARNAP, PNUD, 1997, p. 81; la expresión del conflicto ambiental aparece a 
a preocupaciones ambientales que tiene como centro aspectos de violencia social, que puede derivar en afectaciones y violencia contra el ambiente, paradojalmente, bloqueos, quemas, arrojo de sustancias nocivas a los ecosistemas como parte de la protesta, entre otros. A nuestro modo de ver la violencia socioambiental es consecuencia de diversos factores tales como:

- La escasez y reducción en el acceso a los recursos ambientales de parte de las poblaciones y países, por la escasez potencial y progresiva; por ejemplo el caso del agua dulce y su latente violentogénesis.

- La falta de equidad en la participación en los beneficios generador por el aprovechamiento de tales recursos.

- La necesidad de reducir los impactos ambientales negativos y la reivindicación de derechos a la salud, a la tierra, al ambiente etcétera.

$\mathrm{Al}$ respecto la Defensoría del Pueblo ${ }^{92}$ identifica como causas de los conflictos socioambientales:

1. El problema ambiental, la sensación de incertidumbre y el temor a la contaminación.

2. El problema social: exclusión, desigualdad y discriminación.

3. Afectación de los derechos fundamentales.

4. Actuación del Estado en los conflictos socioambientales: problemas en la gestión y en la institucionalidad ambiental como fuente de desconfianza de la población en el Estado.

mediados del siglo XX. En 1950 la contaminación por mercurio en la bahía de Minamata en Japón, en donde la empresa Chisso Corp. Chemical, productora de cloruro de vinilo y acetaldemical contaminó las aguas marinas durante varios años. La empresa Chisso reconoció hasta 1968 su responsabilidad en el incidente. En 1992 con la conferencia de las Naciones Unidas sobre el Medio Ambiente y Desarrollo (CNUMAD), se revaloró la importancia de las personas y la calidad de su vida sobre los procesos de desarrollo económico. También incluye la prevención y responsabilidad de los gobiernos sobre estos temas, al grado de que su difusión está permeando las estructuras jurídicas, político-institucionales y de comportamientos sociales amplios, sensibilizándolos sobre los problemas ambientales. Si bien es cierto que existen dos escuelas teóricas en el tema, una referida al conflicto ambiental y otra al conflicto socioambiental. Mientras en la primera los países industrializados hablan de las dificultades para que las externalidades ambientales sean asumidas por quienes las generan, en la segunda las tensiones se suscitan por la dificultad para definir la propiedad y distribución de los recursos. Informe Extraordinario. «Los conflictos socioambientales por actividades extractivas en el Perú. Versión al 16 de abril de 2007, que incluye las notas aclaratorias presentadas al Congreso de la República en la misma fecha. 
5. Las externalidades ambientales negativas y su impacto en actividades económicas distintas a las extractivas.

6. Actuación de las empresas en los conflictos socioambientales.

En cuanto a las consecuencias de los conflictos socioambientales, la Defensoría del Pueblo alude a:

\section{IMPACTOS ECONÓMICOS}

Se pone en evidencia, además, que la protección de los derechos fundamentales de las personas, la protección de su espacio vital y del ambiente, constituyen un requisito para garantizar a las inversiones un clima social favorable a su desarrollo. En ese sentido, mantener la debilidad de la institucionalidad ambiental y no avanzar en la integración y mejora de la regulación ambiental puede convertirse en factores que amenacen el desarrollo de las inversiones.

\section{IMPACTOS SOCIALES}

Otro problema social que se advierte es el debilitamiento de una cultura de diálogo entre los ciudadanos, las empresas y el Estado para resolver sus conflictos. La ausencia de mecanismos de diálogo institucionalizados, para que el ciudadano pueda canalizar sus demandas ante la autoridad, así como el incumplimiento reiterado de los compromisos asumidos en procesos de diálogo anteriormente realizados, han generado desconfianza y conducen a la población a utilizar mecanismos de protesta y de fuerza como instrumentos para ser escuchados.

\section{IMPACTOS POLÍTICOS}

Los conflictos socioambientales están dificultando la consolidación de la institucionalidad intermedia que se busca promover a través de importantes procesos como la descentralización. La debilidad de las autoridades regionales y locales para transformar los conflictos en espacios de diálogo ha llevado a la población a exigir «Comisiones de Alto Nivel» que acentúan más dichas debilidades. 
Entre las tendencias de la conflcitividad que advierte el estudio en mención ${ }^{93}$, cabe mencionar:

1. Incremento de demandas ciudadanas respecto a los asuntos socioambientales.

2. Tendencia a catalogar las actividades extractivas como generadoras de pobreza y no de riqueza.

3. Demandas de participación ciudadana entendidas como un derecho a veto.

4. Percepción sobre el Estado como promotor de inversiones antes que protector del ambiente y del espacio vital de las comunidades.

5. Tendencia a responsabilizar solo a las empresas de aquello que también es responsabilidad del Estado. ${ }^{94}$

\section{Ultílogo. Derechos, desastre y ambiente. Una expresión de la relación: derecho violencia y ambiente}

\subsection{InTRODUCCIÓN}

Las relaciones entre desastre ${ }^{95}$ y ambiente son de los más variadas y complejas y conllevan a la necesaria integración de diversos enfoques, a fin de lograr una adecuada comprensión y actuación social frente a ellos. En el plano internacional, el tema concita el interés de las Naciones Unidas, entre otras entidades globales o regionales; al igual que en lo nacional (v.g.

93 Ob. cit., pp. 51 y ss.

94 Ib., p. 76. «La Defensoría del Pueblo ha observado que la sensibilidad por el tema ambiental no siempre es integral en la población y en las organizaciones de la sociedad civil. Para citar un ejemplo, algunos sectores poblacionales que se oponen a las actividades extractivas perciben a estas como más nocivas y peligrosas que los efectos causados por la falta de tratamiento de aguas residuales domésticas e industriales y de los residuos sólidos de las ciudades. Dicha situación también muestra que la valoración del ambiente, la salud y la vida se ve altamente influenciada y —en ciertos casos-condicionada a la información y a la educación que la población recibe. Por lo expuesto, también es importante que la población y las organizaciones de la sociedad civil conozcan y comprendan la complejidad de los temas ambientales porque así se podría impulsar una mayor colaboración y compromiso de la ciudadanía con el medio ambiente y la gestión ambiental.».

95 Sobre el tema Desastres y ambiente, ver Boletín del IDEA PUCP. Año 3, № 15 - Enero 2006. 
INDECI $)^{96}$. Ciertamente los desastres —y los riesgos ${ }^{97}$ que aparejanriesgos irrumpen contra las condiciones ambientales — sean naturales o culturales - sin embargo, en muchos casos, es el propio ser humano quien las propicia o potencia debido a su imprudencia o imprevisión (factor antropogénico), acrecentando de este modo la vulnerabilidad del entorno y el impacto de los desastres sobre su propias condiciones de habitabilidad, subsistencia y calidad. En este contexto, la pobreza en particular, representa un escenario de mayor vulnerabilidad ambiental y socio cultural. La cultura de la prevención debe constituirse en una política de Estado, para no tener que lamentar víctimas y costos —incluyendo los ambientales - que se pueden reducir de manera razonable sobre la base de una oportuna prevención y sistemas de institucionales de alerta confiables y de atención debida.

96 «Manual básico para la estimación del riesgo, Lima - Perú, 2006». Instituto Nacional de Defensa Civil, Dirección Nacional de Prevención, DINAPRE unidad de estudios y evaluación de riesgos UEER. <http://bvpad.indeci.gob.pe/doc/pdf/esp/doc319/doc319 contenido.pdf $>$.

97 Terminología: Términos principales relativos a la reducción del riesgo de desastres. Tomado de: <http://www.eird.org/esp/terminologia-esp.htm > .

Amenaza / peligro. Evento físico, potencialmente perjudicial, fenómeno y/o actividad humana que puede causar la muerte o lesiones, daños materiales, interrupción de la actividad social y económica o degradación ambiental [...].

Amenaza biológica. Procesos de origen orgánico o transportados por vectores biológicos, incluidos la exposición a microorganismos patógenos, toxinas y sustancias bioactivas, que pueden causar la muerte o lesiones, daños materiales, disfunciones sociales y económicas o degradación ambiental. [...].

Amenaza geológica. Procesos o fenómenos naturales terrestres, que puedan causar pérdida de vida o daños materiales, interrupción de la actividad social y económica o degradación ambiental. [...].

Amenazas hidrometeorólogicas. Procesos o fenómenos naturales de origen atmosférico, hidrológico u oceanográfico, que pueden causar la muerte o lesiones, daños materiales, interrupción de la actividad social y económica o degradación ambiental. [...].

Amenazas naturales. Procesos o fenómenos naturales que tienen lugar en la biósfera que pueden resultar en un evento perjudicial y causar la muerte o lesiones, daños materiales, interrupción de la actividad social y económica o degradación ambiental. [...]. Amenazas tecnológicas. Amenaza originada por accidentes tecnológicos o industriales, procedimientos peligrosos, fallos de infraestructura o de ciertas actividades humanas, que pueden causar muerte o lesiones, daños materiales, interrupción de la actividad social y económica o degradación ambiental. [...].

Análisis de amenazas / peligros. Estudios de identificación, mapeo, evaluación y monitoreo de una(s) amenaza(s) para determinar su potencialidad, origen, características y comportamiento. [...]. 


\subsection{LA TECNOLOGÍA Y LOS DESASTRES}

La historia puede ser interpretada como un proceso de expansión de la tecnósfera (esfera de lo artificial creado por el hombre) sobre la naturaleza (ecósfera) y las interrelaciones (sinergia) que ello conlleva. Modernamente el impacto tecnosférico nos ha llevado a la consabida crisis ambiental. El nuevo paradigma ecológico pretende restaurar o al menos reducir dicho impacto, postulando conceptos como tecnologías a escala humana (Schumacher, ITDG), tecnología limpias, ecotecnologías, entre otras. El Acuerdo Nacional y los lineamientos de política ambiental de la Ley General del Ambiente, contemplan el rol de las tecnologías en el marco del desarrollo sostenible. $^{98}$

98 Ley General del Ambiente (Ley 28611). Capítulo 4 Ciencia, Tecnología y Educación Ambiental.

Artículo 123.- De la investigación ambiental científica y tecnológica

La investigación científica y tecnológica esta orientada, en forma prioritaria, a proteger la salud ambiental, optimizar el aprovechamiento sostenible de los recursos naturales y a prevenir el deterioro ambiental, tomando en cuenta el manejo de los fenómenos y factores que ponen en riesgo el ambiente; el aprovechamiento de la biodiversidad, la realización y actualización de los inventarios de recursos naturales y la producción limpia y la determinación de los indicadores de calidad ambiental.

Artículo 124.- Del fomento de la investigación ambiental científica y tecnológica.

124.1 Corresponde al Estado y a las universidades, públicas y privadas, en cumplimiento de sus respectivas funciones y roles, promover:

a. La investigación y el desarrollo científico y tecnológico en materia ambiental.

b. La investigación y sistematización de las tecnologías tradicionales.

c. La generación de tecnologías ambientales.

d. La formación de capacidades humanas ambientales en la ciudadanía.

e. El interés y desarrollo por la investigación sobre temas ambientales en la niñez y juventud.

f. La transferencia de tecnologías limpias.

g. La diversificación y competitividad de la actividad pesquera, agraria, forestal y otras actividades económicas prioritarias.

124.2 El Estado a través de los organismos competentes de ciencia y tecnología, otorga preferencia a la aplicación de recursos orientados a la formación de profesionales y técnicos para la realización de estudios científicos y tecnológicos en materia ambiental y el desarrollo de tecnologías limpias, principalmente bajo el principio de prevención de contaminación.

Artículo 125.- De las redes y registros

Los organismos competentes deben contar con un registro de las investigaciones realizadas en materia ambiental, el cual debe estar a disposición del público, además se promoverá el despliegue de redes ambientales. 


\subsection{La Ciencia y el desarrollo sostenible como fuente material PARA LA PREVENCIÓN Y REDUCCIÓN DE LOS RIESGOS Y DESASTRES}

Las múltiples aristas del desarrollo sostenible, involucran al componente científico como uno de sus soportes fundamentales. La paradoja es que buena parte de los procesos e impactos adversos al ambiente, provienen de las aplicaciones tecnológicas o científicas. Sin incurrir en maniqueísmos entre conservacionistas y desarrollistas, hoy se propende a valores éticos y ponderados, entre ambos lo cual constituye la base del discurso del Desarrollo Sostenible. De otra parte, el paradigma de la ciencia, se reconvierte, con el reconocimiento de los saberes tradicionalmente considerados como «no científicos» pero que hoy adquieren inusitada relevancia, inclusive en el plano comercial y económico. La disputa por los derechos de acceso a tales conocimientos asociados a la biodiversidad así lo demuestra. Por ejemplo, la Unesco — recoge la preocupación sobre los Sistemas de Conocimiento Locales y Autóctonos (LINKS); las políticas y normativas ambientales igualmente confiere nuevos roles a tales saberes. La Agenda 21 (Capítulo 35) enfoca los diversos programas de acción que compete a la Ciencia respecto a los desafíos del Desarrollo Sostenible. Dicho enfoque se refleja igualmente en el Acuerdo Nacional ( $\left.\mathrm{N}^{\circ} 19\right)$. Estos saberes debidamente reorientados mediante políticas adecuadas debieran contribuir a elaborar las normativas a favor de la prevención y reducción de los riegos y desastres 99 .

99 Según Juan E. Musso M.: «Los desastres naturales pueden ser considerados de tres tipos: Los propiamente producidos por distintos componentes de la naturaleza y que se explican por las propias dinámicas que se suceden en las interrelaciones físicas de sus elementos. Los terremotos, los huracanes, los tsunamis, las precipitaciones, las erupciones, las sequías, las inundaciones, los aluviones, etc. Son, entre otras, las expresiones más comunes que como desastres naturales se suceden en muchos de los rincones del mundo. Hay un segundo tipo de desastres, los propiamente artificiales producidos por la mano del hombre y que se explican por las dinámicas políticas, sociales y económicas que se suceden en las interrelaciones de sus obras. Chernovyl en usinas atómicas, Bhopal en industrias químicas, Anchorage en el transporte petrolero, Sahel en hambrunas, etc. Las hay de muchos tipos y las fronteras no las pueden detener. Finalmente hay un tercer tipo de desastres, que son una combinación de los dos tipos anteriores, y que cuando se suceden conllevan perversos efectos en el incremento de sus magnitudes. Esto se está evidenciando como consecuencia del supuesto desarrollo, progreso y bienestar. Los huracanes en el golfo y el cambio climático, Nueva Orleáns y la rotura de diques causados por el huracán, California e Indonesia y los incendios forestales, la avalancha de Maracaibo, etc. En estos últimos, las causas suelen estar en 


\subsection{Política Derecho y desastres}

Los desastres se caracterizan por su capacidad para irrumpir - o interrumpir de modo grave e intenso la cotidianidad y las condiciones normales en la vida de una población; permiten mostrar un conjunto de debilidades, vulnerabilidades e impactos sociales, ecológicos, institucionales, políticos, jurídicos, entre otros. Si el Derecho por antonomasia representa un determinado orden establecido en la vida social, una cierta normalidad social, el desastre por el contrario constituye la negación, la ruptura inevitable de dicho orden; se presenta como una patología del Derecho; pero también como una desafío dinámico para su recreación ${ }^{100}$. Los desastres desencadenar múltiples consecuencias jurídicas relativas a las conductas y responsabilidades de las personas el funcionamiento de las instituciones.

Desde una perspectiva política, la Asamblea General de las Naciones Unidas, en su $44^{\circ}$ del 22 de diciembre de 1989, adoptó una Resolución que proclamó el Decenio Internacional de la Prevención de las Catástrofes Naturales (DIPCN), para toda la década de 1990. A su turno, la Agenda $21^{101} 1$, Capítulo 7 (Fomento del Desarrollo Sostenible de los Asentamientos Humanos), contempla un conjunto de propuestas de planificación y gestión para tales asentamientos en las regiones propensas a los desastres, destacándose la necesidad de desarrollar «una cultura de seguridad».

Los Estados reconocen — acaso nominalmente- la necesidad de identificar una agenda política con relación a los desastres, para lo cual procuran, entre otras medidas, establecer un marco jurídico sobre diversos aspectos orgánicos o institucionales (v.g. Sistema de Defensa Civil), de derechos y obligaciones ciudadanas, con su respectivo correlato de sanciones; así como mecanismos financieros para la prevención y mitigación de los desastres.

lugares distintos de a donde se sufren los efectos. Las preguntas de fondo están dadas, por ejemplo, en ¿cuán responsable es el progreso de una parte de la humanidad, frente a los actuales daños sucedidos por los desastres?, ¿Es posible el progreso, desarrollo y bienestar de espalda al ambiente local o global?». Boletín del IDEA PUCP, Ob. cit., p. 2.

100 WIESNER, Luis. Desastre y derecho: una aproximación al riesgo tecnológico. Bogotá: Temis, 1991.

101 Agenda 21. Desarrollo sostenible: un programa para la acción. Lima: IDEA PUCP, 1999. 


\subsection{El Derecho ante los desastres y el ambiente}

Las Constituciones suelen incorporar Regímenes de Excepción y ciertos Estados de Emergencia, entre los que se incluyen las catástrofes u otros similares. Es el caso del artículo 137, inc. 1c de la Constitución del Perú (1993) o de Colombia (1991) cuyo artículo 215 alude a "hechos que perturben o amenacen en forma grave e inminente el orden económico, social y ecológico del país, o que constituyan grave calamidad pública». En buena cuenta desde el Derecho se establecen estados de emergencia debido a calamidades, se limitan algunos derechos fundamentales - v.g. La libertad de tránsito- se incrementan o disminuyen las cargas tributarias según los destinatarios, además de una vastísima cantidad de medidas administrativas en como el reordenamiento catastral, de horarios y turnos para actividades como el transporte o comercio. Desde el Derecho Penal se agravan sanciones cuando se obtiene aprovechamiento o ventaja patrimonial al amparo de la emergencia (v.g. el «hurto calamitoso»), o cuando el funcionario o servidor público se apropia o utiliza para sí o para otro caudales o efectos que le fueron confiados (peculado) y que están destinados para fines asistenciales o programas de apoyo social, como los desastres u otros similares.

La disrupción del orden jurídico a causa de los desastres, se ofrece como un escenario propicio para la incursión en una variedad de conductas ilícitas (v.g. saqueos, especulación y adulteración de productos de primera necesidad, corrupción, violaciones, peculado y malos manejos de la cosa pública, abuso del poder e impunidad). Sin embargo, desde un ángulo positivo, los desastres representan un desafío al Derecho, al dar clarinadas de alerta a las burocracias ante el imperativo y exigencias sociales o ciudadanas de contar con respuestas inminentes, funcionales y oportunas frente a lo intempestivo de los desastres. En particular, los desastres también conllevan un conjunto de consecuencias o impactos ambientales, al desestabilizar el hábitat humano, así como su correspondiente base de recursos naturales. Muchas normas ambientales tienden a intervenir en relación con ello.

La Ley General del Ambiente prevé en la Gestión Ambiental la Declaratoria de Emergencia Ambiental (artículo 28), normas transitorias de calidad ambiental de carácter especial debido a desastres (artículo 29), los planes de desarrollo (artículo 68) o en el caso de los ecosistemas frágiles (artículo 99). 
En particular la Ley 28804 sobre Declaratoria de emergencia ambiental, regula el procedimiento para declarar en emergencia ambiental una determinada área en caso de ocurrencia de algún daño ambiental súbito y significativo que deteriore el ambiente, que genere un problema de salud pública como consecuencia de la contaminación del aire, el agua o el suelo; ameritando la acción inmediata sectorial a nivel local o regional; reglamentada por el Decreto Supremo 024-2008-PCM.

A veces los efectos sociales y ambientales de un desastre se potencian por la propia acción humana (factor antropógenico), sea por desinformación, necesidad o pobreza, al asentarse en zonas vulnerables o riesgosas, por negligencia en las construcciones y medidas de prevención y mitigación; muchas veces más que prevenir o mitigar, a fortiori, se genera mayor efecto social y ambiental respecto lo que se pretendía controlar ${ }^{102}$.

102 Algunas fuentes sobre Desastres y ambiente:

International Strategy for Disaster Reduction <http://www.unisdr.org/ $>$.

Resolución aprobada por la Asamblea General 58/214. Estrategia Internacional de Reducción de Desastres < http://www.unisdr.org/eng/about_isdr/basic_docs/GA-resolution/ a-res-58-214-esp.pdf $>$.

Estrategia Internacional para la Reducción de Desastres para América Latina y el Caribe $<$ http://www.eird.org/index-esp.html > .

«Reducción del Riesgo de desastres a través de la Gestión Ambiental: Uso de Instrumentos Económicos». Informe Preliminar (BID). Enero, 2004. Luis Carrera de la Torre, Iván Izurieta <http://idbdocs.iadb.org/wsdocs/getdocument.aspx?docnum $=647209>$.

Desastres naturales y su influencia en el medio ambiente. Norma Carrillo H. y Enrique Guadalupe G. <http://sisbib.unmsm.edu.pe/bibvirtual/ publicaciones/geologia/Vol_ IVN\%C2\%B07/desast_nat.htm > .

Hacia una cultura de prevención en desastres desde la educación. Memoria del Seminario-Taller Internacional sobre Prevención y Atención de Desastres en la Educación Lima, Perú-noviembre 2003 <itdg.org.pe/archivos/desastres/Memoriaeducacion.pdf > .

Planificación y protección financiera para sobrevivir los desastres Kari Keipi y Justin Tyson < http://idbdocs.iadb.org/wsdocs/getdocument.aspx?docnum $=562538>$.

La Red de Estudios Sociales en Prevención de Desastres en América Latina (LA RED) $<$ http://www.desenredando.org/>.

Reducción de Vulnerabilidad a los Peligros Naturales en las Américas. Comisión Interamericana para el Desarrollo Sostenible. OEA, Washington D.C. Cidi/Cids/Res. 5 (II-O/99).

< http://www.summit-americas.org/Sustainable\%20Dev/Resoluci\%C3\%B3n\%205-II0-99.htm >.

Natural Disaster Reduction UNESCO < http://www.unesco.org/science/earth/disaster/ index_disaster.shtml > .

Kuroiwa, Julio. Reducción de desastres: viviendo en armonía con la naturaleza Lima: PNUD, 2002.

Atlas de peligros naturales del Perú. Lima: Instituto Nacional de Defensa Civil (Perú). 


\section{Conclusión}

Las relaciones entre el Derecho —o si se quiere los sistemas jurídicoscon la violencia, requieren una mirada interdisciplinaria y multiforme. Los nuevos paradigmas impactan a los sistemas jurídicos así como a las relaciones que estos establezcan con los diferentes aspectos de la realidad. La dimensión ambiental alimentada por esos paradigmas se impregna en tales relaciones, de suerte que para el caso en estudio es evidente la interconexión Derecho Ambiente y Violencia conforme los fundamentos desarrollados, que de algún modo tienen como sustento enfoques críticos del sistema legal, aportes de un Derecho Ambiental no tan entusiastamente antropocéntrico, de las vertientes de la Ecología Política y de alguna manera de la moderna complejología ${ }^{103}$.

103 EARLS, John. Introducción a la teoría de sistemas complejos. Lima: IDEA-PUCP, 2007, p. 121. En las últimas décadas, ha surgido un nuevo campo de la ciencia: la teoría de sistemas complejos. Dichos sistemas están constituidos por componentes que interactúan entre sí para dar lugar a comportamientos organizados y tienen propiedades que son diferentes a las de sus componentes (propiedades emergentes). La ciencia de la complejidad se ocupa de los principios generales que gobiernan el comportamiento interno de estos sistemas y sus respectivas manifestaciones sensibles. Así, se encuentra que hay propiedades emergentes comunes en sistemas fisiológicos, ecológicos, socioculturales y económicos < http://agenda.universia.edu.pe/pucp/2008/04/03/introduccion-ala-teoria-de-los-sistemas-complejos $>$. 